\title{
ОСОБЕННОСТИ СОТРУДНИКОВ, ЗАНЯТЫХ ИНТЕЛЛЕКТУАЛЬНЫМ ТРУДОМ, ИХ ОБРАЗОВАНИЯ И РАЗВИТИЯ
}

\author{
(c) 2021 Шатохина Дарья Дмитриевна \\ факультет технологического менеджмента и инноваций, преподаватель \\ Национальный исследовательский университет ИТМО, Россия, Санкт-Петербург \\ E-mail: ddshatokhina@itmo.ru
}

Сотрудники, занимающиеся интеллектуальным трудом, являются основой формирования и развития интеллектуального капитала. В исследовании были выявлены особенности данных сотрудников, и предложены принципы, позволяющие вести их обучение и подготовку с учетом требований самих сотрудников, бизнеса, образовательных учреждений и инновационной деятельности компаний.

Ключевые слова: стратегия управления, инновационные проекты, интеллектоемкая сфера, интеллектоемкие компании, человеческий капитал, интеллектуальный капитал, управление инновационными проектами, интеллектуальный труд, геймификация, edutainment.

Развитие инновационных, передовых отраслей является одним из приоритетных направлений в экономике России. При этом данные отрасли нуждаются в сотрудниках, которые были бы интеллектуально инициативны, брали ответственность за собственные решения и выступали в качестве новаторов и ключевых инициаторов развития и повышения качества интеллектуального капитала организаций. Подобные отрасли, где от нематериальных и интеллектуальных ресурсов компании зависит конкурентоспособность и существование компании на рынке, образуют интеллектоемкую сферу. Именно в данной сфере сотрудники, занимающиеся интеллектуальным трудом, созданием новых решений, становятся важнейшим ресурсом организации, от развития и подготовки которого во многом зависит ее будущее. Как показывают исследования и международные рейтинги, например, Глобальный инновационный индекс - 2020, человеческий капитал в составе интеллектуального и сотрудники, занимающиеся научными исследованиями и разработками, на сегодняшний момент являются сильной стороной инновационной деятельности в России и преимуществом российской инновационной системы. В то же время необходимо отметить, что управленческие методы и проблемы, например, строгая иерархичность, формализованность, бюрократизация отрицательно влияют на развитие данного фактора инновационной деятельности страны. По оценкам исследователей [23], в настоящий момент мировые тенденции в сфере стратегического менеджмента уходят от классического строго формализированного планирования к гибкой и настраиваемой в процессе системе, которая позволяет совместить несколько междисциплинарных подходов и обогатить стратегическое управление новыми методами. При этом мировые форс-мажорные события (например, пандемия COVID-19) и глобальные тренды только усиливают формирование новых подходов в стратегическом менеджменте. Эта тенденция заставляет все глубже изучать особенности ключевой составляющей интеллектоемкой сферы, а именно сотрудников, занимающихся интеллектуальным трудом и созданием нового - поскольку именно их работа является основополагающим фактором для развития интеллектуального капитала компаний, а значит, формируемые подходы в стратегическом управлении должны учитывать данные особенности для наилучшего результата.

Вопросами изучения сотрудников, занимающихся интеллектуальным, творческим, новационным трудом занимались такие авторы, как П.Друкер [14], П. Флад [15], Т.Е.Андреева [1], Е.Е.Юртайкин, Т.А.Солтицкая [2], С.Г.Михнева [4], Г.Н.Константинов, С.Р. Филонович и другие. На основе их трудов возможно выделить факторы, позволяющие характеризовать персонал организации как занятый интеллектуальным или творческим трудом и созданием нового. Именно момент разработки нового, новой ценности является в том числе ключевым в определении важности данных сотрудников для развития 
интеллектуального капитала компании. Ниже представлены факторы, на основе которых данные авторы предлагают выделение сотрудников, занимающихся интеллектуальными задачами (также в работах российских авторов встречается понятие «сотрудники умственного труда»), в особую, отдельную категорию:

1. Доля интеллектуального труда в ежедневной работе и задачах сотрудников. Данный фактор упоминается в работах таких российских авторов, как Т.Е.Андреева [1], Е.Е.Юртайкин, T.А.Солтицкая [2], а также более ранних трудах таких зарубежных исследователей, как П. Друкер [14] и П.Флад [15]. При этом в анализе данного фактора важно опираться на понимание интеллектуального труда как труда новационного, творческого, требующего большой смелости и активности от человека, что накладывает определенные ограничения на исследование и требования к персоналу. Результаты данного труда могут быть выражены в объектах интеллектуальной собственности.

2. Доля информации и знаний в ресурсах, требуемых для работы сотрудников. Данный фактор выделяется, например, такими исследователями, как П.Друкер, Г.Н.Константинов, С.Р.Филонович. Чем выше ежедневный объем данных знаний и информации, чем больше объем данных, с которыми приходится ежедневно работать сотруднику, тем больше вероятность отнесения его к исследуемой категории.

3. Фактор профессии. Изначально был выделен для отделения данных сотрудников от сферы услуг, однако в настоящее время также подвергается обсуждениям и критике с точки зрения различных исследований. Разделяя данную точку зрения относительно устаревания данного фактора, видится необходимым упомянуть, что сфера услуг на данный момент также может использовать передовые технологичные решения, что требует все большей квалификации от сотрудников, занятых в ней.

4. Уровень образования. Первоначально выделялся исследователями, полагавшими, что наличие высшего образования позволяет выделять сотрудников в изучаемую категорию работников, занятых интеллектуальным трудом, однако в настоящее время является спорным, так как повышается число случаев, когда для выполнения нестандартной, творческой, новационной работы наличие высшего образования не является категоричной необходимостью.
5. Способность создавать новое, творческие способности, креативность. Данный фактор выделяют в том числе как основу характеристики креативного класса - людей, в чьи профессиональные задачи входит формирование новых ценностей, новых знаний и идей. Р. Флорида [7] характеризует данную категорию населения стремлением к горизонтальному развитию карьеры, предпочтением к творческим задачам, наличием творческого мышления и способностью к нестандартному решению задач.

Однако, как видим, с учетом развития интеллектоемкой сферы и повышения требований к новационному, интеллектуальному труду, а также самостоятельности и активности сотрудников интеллектоемких компаний, описанные выше факторы, позволяющие отнести персонал компании к категории сотрудников, занятых интеллектуальным трудом и созданием нового, являются недостаточными: некоторые из них устарели, некоторые прошли определенное развитие и воспринимаются иначе. Данная же категория работников критично важна для формирования и развития, повышения качества интеллектуального капитала компании, что важно для ее конкурентоспособности и эффективности. Поэтому определим непосредственно само понятие «сотрудники, занятые интеллектуальным и/или творческим трудом и созданием нового» и сформируем классификацию, позволяющую структурировать и разграничить типы сотрудников по особенностям их труда и необходимых, важных для выполнения профессиональных задач личностным характеристикам.

Сотрудники, занятые интеллектуальным и/или творческим трудом и созданием нового сотрудники, чей профессиональный труд характеризуется спецификой регулярных задач, формой и требованиями к ожидаемым результатам труда и требованиями компании к личным качествам, позволяющим эффективно использовать и качественно развивать интеллектуальный капитал компании.

Упомянутая выше классификация персонала приведена в табл. 1. В ней предлагается разделение сотрудников на 3 типа: занятые рутинным трудом, занятые интеллектуальным трудом и занятые интеллектуальным и/или творческим трудом в совокупности с созданием нового. Именно создание нового является одним из наиболее сложных процессов, как с точки зрения особенностей работы человеческого мыш- 
Таблица 1. Классификация сотрудников по специфике их труда и требуемых для выполнения профессиональных задач личностных характеристик

\begin{tabular}{|c|c|c|c|}
\hline \multirow{2}{*}{$\begin{array}{l}\text { Критерий классифика- } \\
\text { ции }\end{array}$} & \multicolumn{3}{|l|}{ Группы сотрудников } \\
\hline & $\begin{array}{l}\text { Сотрудники рутинного } \\
\text { труда }\end{array}$ & $\begin{array}{l}\text { Сотрудники интеллек- } \\
\text { туального труда }\end{array}$ & $\begin{array}{l}\text { Сотрудники интеллек- } \\
\text { туального, творческого } \\
\text { труда, занятые созда- } \\
\text { нием нового }\end{array}$ \\
\hline \multicolumn{4}{|c|}{ Критерии, относящиеся к труду личности } \\
\hline $\begin{array}{l}\text { Преимущественный } \\
\text { тип труда }\end{array}$ & $\begin{array}{l}\text { Преимущественно рутин- } \\
\text { ный, шаблонный труд }\end{array}$ & $\begin{array}{l}\text { Имеется доля рутинного } \\
\text { труда, однако присутству- } \\
\text { ет творческий и неша- } \\
\text { блонный }\end{array}$ & $\begin{array}{l}\text { Новационный, интеллек- } \\
\text { туальный, творческий }\end{array}$ \\
\hline $\begin{array}{l}\text { Преимущественный } \\
\text { тип создаваемой инно- } \\
\text { вации }\end{array}$ & - & $\begin{array}{l}\text { Поддерживающие инно- } \\
\text { вации }\end{array}$ & $\begin{array}{l}\text { Прорывные, подрывные, } \\
\text { поддерживающие инно- } \\
\text { вации }\end{array}$ \\
\hline $\begin{array}{l}\text { Доля разработки нового } \\
\text { в профессиональных } \\
\text { обязанностях }\end{array}$ & Практически отсутствует & $\begin{array}{l}\text { Могут быть как более } \\
\text { сосредоточены на под- } \\
\text { держании существующих } \\
\text { процессов, так и иногда } \\
\text { включаться в создание } \\
\text { нового }\end{array}$ & $\begin{array}{l}\text { Преимущественная } \\
\text { доля разработки нового, } \\
\text { рутинные обязанности } \\
\text { присутствует в неболь- } \\
\text { шом количестве }\end{array}$ \\
\hline $\begin{array}{l}\text { Выражение результата } \\
\text { труда }\end{array}$ & $\begin{array}{l}\text { Не выражается в объектах } \\
\text { ИС }\end{array}$ & $\begin{array}{l}\text { В большинстве случаев } \\
\text { не выражается в объектах } \\
\text { ИС } \\
\end{array}$ & $\begin{array}{l}\text { Объекты ИС, их усовер- } \\
\text { шенствования, дополне- } \\
\text { ния, развитие }\end{array}$ \\
\hline \multicolumn{4}{|c|}{ Критерии, относящиеся к личности и проявляющиеся во время труда } \\
\hline $\begin{array}{l}\text { Способность к созда- } \\
\text { нию нового (творческие } \\
\text { способности, креатив- } \\
\text { ность) }\end{array}$ & $\begin{array}{l}\text { Имеется, не используется } \\
\text { регулярно в профессио- } \\
\text { нальной деятельности }\end{array}$ & $\begin{array}{l}\text { Имеется, используется } \\
\text { нерегулярно в професси- } \\
\text { ональной деятельности, } \\
\text { при совпадении опреде- } \\
\text { ленных условий }\end{array}$ & $\begin{array}{l}\text { Имеется, используется } \\
\text { на регулярной основе в } \\
\text { профессиональной дея- } \\
\text { тельности }\end{array}$ \\
\hline $\begin{array}{l}\text { Мотивация к созданию } \\
\text { нового }\end{array}$ & $\begin{array}{l}\text { Отсутствует изначальная } \\
\text { внутренняя мотива- } \\
\text { ция, может появляться } \\
\text { под влиянием внешних } \\
\text { условий }\end{array}$ & $\begin{array}{l}\text { Зависит от ситуации и } \\
\text { условий, может иметься } \\
\text { как внутренняя, так и } \\
\text { проявляться под влияни- } \\
\text { ем внешних условий } \\
\end{array}$ & $\begin{array}{l}\text { Имеется стойкая вну- } \\
\text { тренняя мотивация или } \\
\text { внешние условия стойко } \\
\text { мотивируют ее }\end{array}$ \\
\hline $\begin{array}{l}\text { Способность к аналити- } \\
\text { ческим действиям, опе- } \\
\text { рированию большими } \\
\text { объемами информации }\end{array}$ & $\begin{array}{l}\text { Имеется, не использует- } \\
\text { ся в профессиональной } \\
\text { деятельности }\end{array}$ & $\begin{array}{l}\text { Имеется, используется } \\
\text { на регулярной основе в } \\
\text { профессиональной дея- } \\
\text { тельности }\end{array}$ & $\begin{array}{l}\text { Имеется, используется } \\
\text { на регулярной основе в } \\
\text { профессиональной дея- } \\
\text { тельности }\end{array}$ \\
\hline $\begin{array}{l}\text { Способность действо- } \\
\text { вать в условиях неопре- } \\
\text { деленности }\end{array}$ & $\begin{array}{l}\text { Имеется, не проявлена в } \\
\text { регулярной профессио- } \\
\text { нальной деятельности }\end{array}$ & $\begin{array}{l}\text { Имеется, проявляется от } \\
\text { случая к случаю в профес- } \\
\text { сиональной деятельности }\end{array}$ & $\begin{array}{l}\text { Имеется, проявляется ре- } \\
\text { гулярно и часто, решения } \\
\text { принимаются с мини- } \\
\text { мальным количеством } \\
\text { данных }\end{array}$ \\
\hline
\end{tabular}

ления, так и с точки зрения дальнейшей апробации и реализации предлагаемых идей, поэтому данный процесс позволяет выделить отдельный тип сотрудников, занимающихся формированием каких-либо новых ценностей в рамках собственных ежедневных профессиональных задач.

Таким образом, данная классификация позволяет проанализировать сотрудников организации или отдельных структур и команд внутри компании, выявить наиболее частые и преобладающие типы сотрудников и учитывать их особенности при формировании и внедрении стратегических и тактических решений компании относительно развития организации, управления инновационной деятельностью и инновационными проектами компании, HR-политики, внутреннего брендинга, well-being программ, бренд-стратегии, коммуникационной стратегии и т.д.

Говоря об особенностях сотрудников, занятых интеллектуальным трудом и созданием нового, факторах, которые позволяют их определять, нельзя не затронуть тему образования и развития данных сотрудников. Все больше компаний уделяют внимание внутрикорпоративному образованию собственных работников, 
созданию комфортной среды для их труда, возможностям заботы о физиологическом и психологическом здоровье персонала организации, особенно в высокотехнологичных отраслях, составляющих значительную часть интеллектоемкой сферы $[5,9]$. При этом не менее важным процессом является подготовка и обучение данного типа сотрудников в том числе до того, как они станут частью компании - то есть в образовательных учреждениях. Совокупность тесных социальных связей между сотрудниками различных отделов и организаций и развитие их междисциплинарных навыков, совместное обогащение знаниями и навыками не только положительно сказывается на внедрении инноваций в деятельность компаний, но и помогает поддерживать конкурентоспособность организации за счет развития бизнес-процессов $[6,18,19]$. Спецификой экономики знаний и интеллектоемкой сферы также являются высокие требования к уникальному набору компетенций и навыков каждого специалиста, сформировать который возможно в индивидуальных образовательных траекториях, которые должны быть выстроены таким образом, чтобы обеспечивать как приобретение узкоспециализированных, так и широких, базовых профессиональных и личностных навыков [16, 17]. Таким образом, за формирование подобных навыков и компетенций будущих сотрудников интеллектоемких компаний в том числе отвечают университеты - как аккумуляторы образовательных, социальных и профессиональных возможностей для студентов и преподавателей. Университет является субъектом особого типа, который формирует и наращивает собственный интеллектуальный капитал, далее распространяющийся через социальные и академические связи и уже становящийся в свою очередь частью интеллектуального капитала компаний и некоммерческих организаций $[11,21]$. Этот процесс позволяет выделить особую роль университетов в формировании интеллектуального капитала и повышении его качества сразу среди большого ряда компаний, так или иначе контактирующих с университетом, его выпускниками и сотрудниками [22].

По мнению отдельных исследователей, способствовать данному процессу качественной подготовки будущих сотрудников интеллектоемких компаний также могут интегрированные образовательные проекты «комплексы мероприятий, направленные на по- лучение знаний нескольких типов (академические, специализировано-профессиональные), а также практических навыков, соединяющие разнообразные форматы, целевые аудитории и аккумулирующие в себе взаимодействие образовательных учреждений и бизнеса» [10]. Отличительной особенностью данных проектов является их ориентация на потребности задействованных субъектов - самих обучающихся, образовательных учреждений и бизнеса - и соединение внутри проекта таких составляющих, как академическое обучение, специализированное узконаправленное обучение, практические навыки и самостоятельная работа обучающихся. В результате интегрированные образовательные проекты становятся точкой сборки для заинтересованных в формировании и развитии человеческого, и как следствие, интеллектуального капитала субъектов: представителей бизнеса, образовательных учреждений и непосредственно студентов. Эффект синергии, по мнению исследователей, достигается при использовании механик обучения, нацеленных на развитие проактивности, креативного мышления, творческого подхода и задействования для этого всех возможностей упомянутых субъектов.

На формирование и использование подобных механик в том числе нацелены тренды в области образования, ставшие за последние годы глобальными: геймификация и edutainment. Геймификация в образовании позволяет повысить мотивацию, вовлеченность обучающихся благодаря использованию игрового дизайна в образовательной среде [13]. При этом исследователи отмечают, что вопросы геймификации образовательного контекста являются достаточно сложными для изучения и эксперимента, хотя изучение геймификации в различных отраслях позволяет говорить о том, что игровой опыт повышает смелость и активность участников, нестандартность используемых ими решений и предлагаемых идей, делает обстановку более открытой и мотивирующей, лояльной к ошибкам и новому опыту.

Тренд на edutainment обозначает подход, объединяющий обучение и игровые технологии, что позволяет делать образование более интерактивным, увлекательным и эмпирическим процессом, при этом, в отличие от геймификации, при этом не требуется разработка полноценного игрового пространства и правил. Многие исследователи, например, Д. Дьюи, говорят о 
важной роли эмоций и активности, инициативы в процессе обучения как основополагающего процесса в человеческой жизни, о необходимости развития игровых навыков, нестандартного мышления и творческого подхода [12]. Использование интерактивных, визуализированных форматов подачи информации способствует лучшему запоминанию и практическому освоению знаний и навыков обучающимися [8]. Таким образом, использование edutainment-подхода позволяет делать образовательную среду более свободной и открытой к новому и совершению ошибок, что развивает инновационную активность будущих сотрудников компаний интеллектоемкой сферы. Подобный подход в том числе работает на повышение человекоориентированности компаний и образовательных учреждений, ведь, как упоминает, например, Н. Ноддингс, «образование должно быть направлено на основную цель и задачу человеческой жизни - счастье» [20].

Практическим примером использования подобных подходов в обучении и подготовке будущих сотрудников, занятых интеллектуальным трудом и/или созданием нового, может служить разработанный автором совместно с А.Н.Булыгиной проект образовательной квест-игры в рамках курса «Маркетинг новых вызовов» от магистерской программы «Инновационный маркетинг» факультета технологического менеджмента и инноваций Университета ИТМО, г. Санкт-Петербург, и проекта Marketorium School, нацеленного на развитие практических навыков у будущего поколения маркетологов. Данная квест-игра была реализована на занятии «Новое позиционирование и брендинг. Пространство смыслов. Новые подходы к формированию бренд-идентичности» в апреле 2021 г.

При разработке концепции данной квест-игры был проведен брифинг с кураторами курса, глубинные интервью с представителями целевой аудитории курса «Маркетинг новых вызовов», а также анализ трендов в сфере практикоориентированного образования. Данный курс изначально ориентировался на две аудитории: начинающие маркетологи и среднего уровня, однако в проведенного исследования был составлен более точный собирательный портрет представителя целевой аудитории курса «Маркетинг новых вызовов»: проактивный начинающий маркетолог, который стремится к постоянному и быстрому развитию в сфере, постоянно ищет новое и хочет учиться вместе с единомышленниками, в том числе, используя удобные и привычные для него технологические инструменты. Для такого человека важно развивать собственные компетенции на практике, учиться при помощи новых, нестандартных и креативных подходов, получать прикладные знания в привычном онлайн-формате, этот специалист боится остаться только в рамках классического образования и стремится получать новые знания из неформальных и современных источников.

Таким образом, целью разработчиков описываемого проекта стало формирование инновационного геймифицированного инструмента для проверки знаний студентов относительно брендинга, который позволил бы в неформальном формате закрепить полученные на занятии знания и стимулировать принятие нешаблонных, смелых решений в процессе игры. В соответствии с данными целями были разработаны образовательные результаты и выбран формат ролевой квест-игры, включающей выбор решений на основе группового обсуждения, нестандартные ситуации для решения, а также ситуации, требующие от студентов использования собственного опыта маркетинговой насмотренности и кругозора. Успешность прохождения игры зависела от решимости студентов использовать нестандартные решения, доверия друг другу и навыка приходить к единому решению в команде, а также широты маркетингового кругозора. Для реализации квест-игры в онлайнформате на платформе ZOOM разработчиками была сформирована нарративная карта квест-игры в Miro (небольшая часть карты представлена на рис. 1), проработана и оформлена интерактивная презентация с заданиями и вариантами для выбора последующих шагов (пример на рис. 2), подготовлена система тестов для голосований.

По итогам реализации данной квест-игры, анализа чата во время игры, отслеживания активности студентов на протяжении всего занятия и сбора обратной связи можно оценить эффективность применения описываемого инструмента. Основные особенности, положительно отмеченные студентами, заключаются в мотивации пройти игру до конца, чтобы узнать сюжет, случившиеся с героем или героиней игры события и итог своих действий, отсутствии страха ошибки, ощущении поддержки от других 


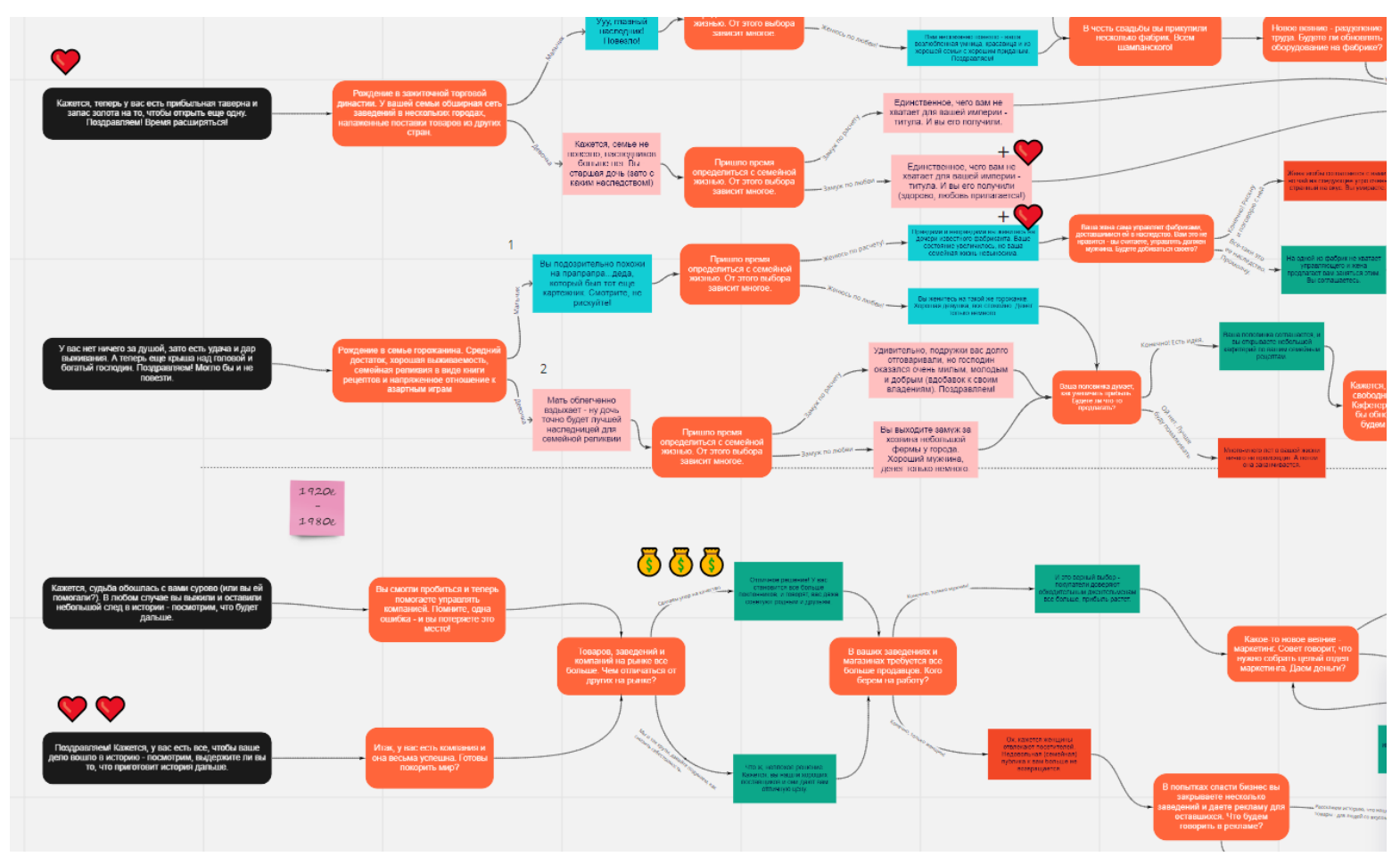

Рисунок 1. Часть нарративной карты для квест-игры в Miro

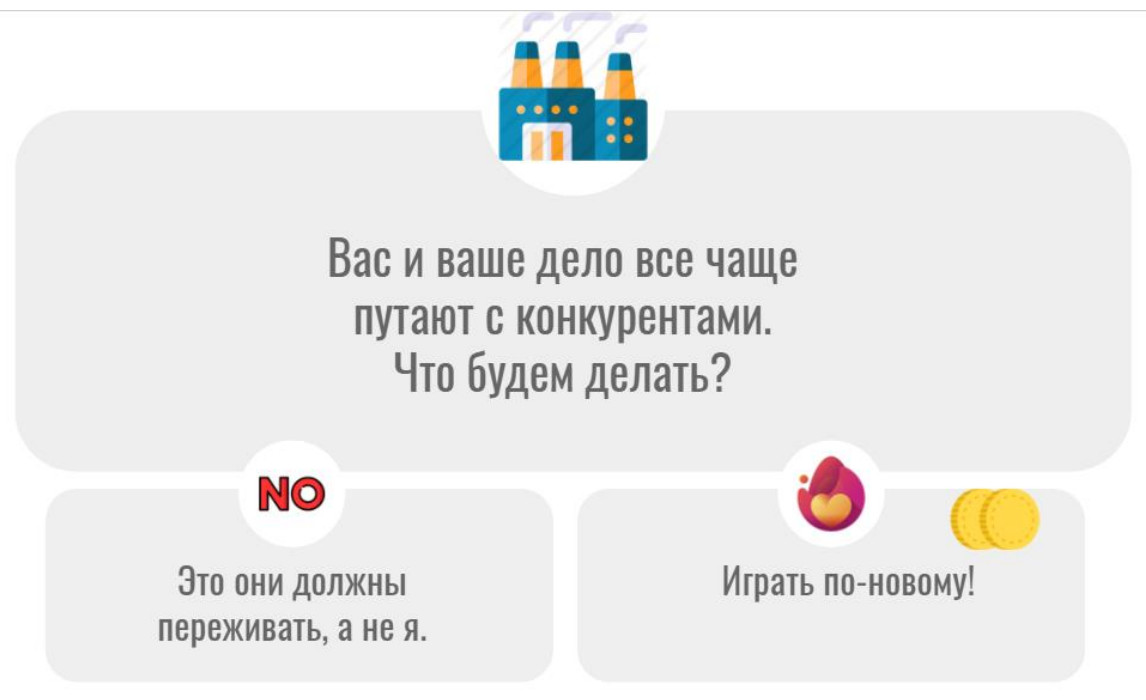

Рисунок 2. Пример слайда из интерактивной презентации с заданием 
участников занятия и преподавателей, легкий и понятный формат и использование полученных на занятии знаний здесь и сейчас. Что же касается вовлечения обучающихся, при обучении в онлайн-форматах внимание часто рассеивается и на основе эмпирического опыта разработчиков проекта можно отметить, что около 40-50\% участников занятий в ZOOM к концу лекции могут отключиться вследствие различных отвлекающих факторов. В то же время, на занятии «Новое позиционирование и брендинг. Пространство смыслов. Новые подходы к формированию бренд-идентичности», где была реализована описываемая квест-игра по брендингу, на последних этапах игры активное участие в ней принимали около 75\% от изначального количества студентов на занятии. Таким образом, можно говорить о том, что интерактивные, основанные на использовании геймификации и edutainment-подходов проекты в образовании положительно влияют на вовлечение обучающихся в процесс, более легкое и быстрое усвоение полученных знаний и развитие таких важных навыков для сотрудников, занятых интеллектуальным и/или творческим трудом и соз- данием нового, как умение ошибаться, использовать нестандартные приемы решения задач, творческое мышление и командная поддержка.

По итогам проведенного исследования особенностей сотрудников, занятых интеллектуальным и/или творческим трудом и созданием нового, а также реализации практического проекта, нацеленного на формирование геймифицированного инструмента для обучения студентов и развития у них творческого мышления, смелости пробовать и принимать нестандартные решения, можно с уверенностью сказать об особой важности данных сотрудников и их подготовки, образования и развития. Именно данный тип сотрудников в компаниях интеллектоемкой сферы является основой инновационной активности, конкурентоспособности и эффективности организации, развития ее интеллектуального капитала. Для обучения подобных сотрудников рекомендуется применять современные интерактивные методы, которые позволяют сделать обучение вовлекающим, неформальным и развивающим проактивность, навык самостоятельной работы и творческого мышления.

\section{Библиографический список}

1. Андреева Т. Е. Работник интеллектуального труда: подход к определению // Вестник Санкт-Петербургского университета. Менеджмент.-2007.- № 4.- С. 32-49.-1

2. Андреева Т. Е., Юртайкин Е.Е., Солтицкая Т. А. Практика развития персонала как инструмент привлечения, мотивации и удержания интеллектуальных работников // Научные доклады. 2006. - № 34 (R). - CПб., 2006.

3. Кобзева Н.A. Edutainment как современная технология обучения // Ученые записки Таврического национального университета им. В. И. Вернадского, серия «Филология. Социальные коммуникации», 2019.- Т. 25 (64) No 1.- С. 3-6.

4. Михнева С. Г. Рынок труда: методологические и теоретические основы познания (системно-эволюционный подход) // Волгоград: Волгогр. гос. техн. ун-т., - 2001.

5. Родионов Д.Г., Величенкова Д. С. Методика оценки эффективности региональной инновационной системы с учетом влияния университетов. Инновации и инвестиции. 2020. № 8. С. 3-7.

6. Родионов Д.Г., Конников Е.А., Алферьев Д.А. Информационный капитал предприятия как целевой показатель развития в рамках цифровых экономических систем // Экономические науки. Общество с ограниченной ответственностью Экономические науки, 2020. № 190. Р. 131-137.

7. Флорида Р. Креативный класс: люди, которые меняют будущее // Классика-ХXI, 2005.- 430 с.

8. Химич E. С. Разработка креативной концепции образовательных проектов на основе трендмаркетинга / ВКР, ФТМИ, Университет ИТМО,-2021.-179 с.

9. Шубина И., Шабалин С. Чего на самом деле хотят разработчики // Inc. [Электронный pecypc] https://incrussia. $\mathrm{ru} /$ understand/what-devs-want

10. Budrin A.G., Soloveva D., Bylugina A., Shatokhina D., Vorobeva A. Integrated educational projects as a methods of human capital development in the knowledge economy // IOP Conference Series: Materials Science and Engineering - 2020, Vol. 940, No. 1, pp. 012102

11. Cricelli L., Greco M., Grimaldi M. (2017), Llanes P. Intellectual capital and university performance in emerging countries, Journal of Intellectual Capital, Vol. 19(1), pp. 71-95

12. Dewey, J. My Pedagogic Creed // School Journal, vol. 54 (January 1897), pp. 77-80. 
13. Dichev, C., Dicheva, D. Gamifying education: what is known, what is believed and what remains uncertain: a critical review // Int J Educ Technol High Educ 14, 9, 2017 // [Электронный ресурс]: https://doi.org/10.1186/s41239-0170042-5

14. Drucker P.F. Knowledge-Worker Productivity: The Biggest Challenge // California Management Review, 1999. Vol. 41. N 2. P. 79-94.

15. Flood P.C., Turner T., Ramamoorthy N, Pearson J. Causes and Consenquences of Psychological Conracts among Knowledge Workers in the High Technology and Financial Services Industries // International Journal of Human Resourse Management. 2001. Vol. 12. N 7. P. 1152-1165.

16. Kelly, G., Mastroeni, M., Conway, E., Monks, K., Truss, K., Flood, P. and Hannon, E. (2011), Combining diverse knowledge: knowledge workers' experience of specialist and generalist roles, Personnel Review, Vol. 40 No. 5, pp. 607-624.

17. Kharlamova T., Kharlamov A. Human capital development in the digitalization risk management process // Conference: Proceedings of the International Conference on Digital Technologies in Logistics and Infrastructure (ICDTLI 2019). 2019.

18. Moiseev, V. \& Sudorgin, O. \& Nitsevich, V. \& Stroev, V. (2020). Social Policy of Russia as the Factor of Development of Human Capital, International Scientific Conference, FarEastCon 2018, Vol.138, pp.706-716.

19. Nahapiet, J., Ghoshal, S. (1998), Social capital, intellectual capital, and the organizational advantage (Article), Academy of Management Review, Vol. 23(2), pp. 242-266.

20. Noddings N. Happiness and Education / Cambridge, UK: Cambridge University Press, 2003.

21. Okorokov R., Timofeeva A., Kharlamova T. Building intellectual capital of specialists in the context of digital transformation of the Russian economy // IOP Conference Series: Materials Science and Engineering. IOP Publishing, 2019. Vol. 497, № 1. P. 12015.

22. Pokrovskaia, N.N., Ababkova, M.Y., Fedorov, D.A. (2019), Educational services for intellectual capital growth or transmission of culture for transfer of knowledge - consumer satisfaction at st. Petersburg universities (Article), Education Sciences, Vol. 9 (3).

23. Vrdoljak-Raguž, I., Jelenc, L., \& Podrug, N. Neostrategic Management - An International Perspective on Trends and Challenges // Switzerland: Springer International Publishing. - 2016. - p. 113-158. 